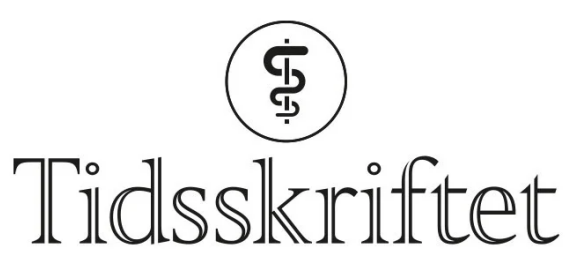

DEN NORSKE LEGEFORENING

\title{
Uterusruptur hos førstegangsfødende
}

\author{
KORT KASUISTIKK
}

SOLVEIG KARBØ ONSTAD

solveigonstad@hotmail.com

Kvinneklinikken

Akershus universitetssykehus

Solveig Karbø Onstad er lege i spesialisering.

Forfatteren har fylt ut ICMJE-skjemaet og oppgir ingen interessekonflikter.

\section{ANDREA SOLNES MILTENBURG}

Kvinneklinikken

Akershus universitetssykehus

Andrea Solnes Miltenburg er ph.d. og lege i spesialisering.

Forfatteren har fylt ut ICMJE-skjemaet og oppgir ingen interessekonflikter.

\section{ELLEN MARIE STRØM-ROUM}

Kvinneklinikken

Akershus universitetssykehus

Ellen Marie Strøm-Roum er ph.d., spesialist i fødselshjelp og kvinnesykdommer og overlege.

Forfatteren har fylt ut ICMJE-skjemaet og oppgir ingen interessekonflikter.

\section{Uterusruptur er en sjelden og alvorlig obstetrisk hendelse. Tidligere gjennomgått keisersnitt er den største risikofaktoren, men også mindre operative inngrep på uterus kan gi økt risiko for ruptur.}

En tidligere frisk, førstegangsfødende kvinne i 20-årene hadde for fire år siden hatt en ekstrauterin graviditet og ble da salpingektomert på høyre side. Grunnet infertilitet gjennomgikk hun tre år senere en diagnostisk laparoskopi med tubeperfusjon. Kvinnen ble etter dette spontant gravid. I svangerskapsuke $42(41+3)$ var hun til overtidskontroll hvor alt ble funnet normalt, med foster i hodeleie og placenta i fundus uteri.

Fødselen ble indusert tre dager senere på grunn av overtidig svangerskap. Ultralydundersøkelsen ved innkomst viste normal mengde fostervann, spontane bevegelser og normale dopplerverdier. Det var ingen bemerkninger vedrørende placenta. Kvinnen fikk tabletter med $25 \mu \mathrm{g}$ misoprostol peroralt, da det mislyktes å legge inn ballongkateter i cervix. Hun fikk i alt fire tabletter med to timers mellomrom. Ved vaginal eksplorasjon før siste tablett fant man lukket cervix. Kardiotokografi (CTG) i forkant av siste tablett viste avvikende fosterlyd og takykardi på 155 slag per minutt (normalområde 
110-150) med normal variabilitet (figur 1). Kvinnen fikk deretter økende rier og ble raskt svært smertepåvirket. Hun ble overflyttet til fødestue en time og ti minutter etter at siste misoprostoltablett ble gitt. CTG-apparatet ble i den forbindelse koblet av. Under overflytting ble abdomen spent, og kvinnen fikk økende smerter, som ikke opphørte mellom riene. Ved påkobling av CTG-apparat etter 13 minutter fant jordmor hjerteaksjon på 70-9o slag per minutt hos fosteret, og lege ble tilkalt. Ultralyd verifiserte bradykardi hos fosteret. Da smertene ble tolket som hyperstimulering med ledsagende tegn på oksygenmangel hos fosteret, ble kvinnen gitt riehemmende medikament i form av 6,75 mg atosiban intravenøst. Det var ingen bedring av fosterlyden etter riehemmende behandling, og kvinnen ble oppfattet som unormalt høyt smertepåvirket. Ved vaginal eksplorasjon fant man fortsatt lukket cervix. Grunnet vedvarende fosterbradykardi ble kvinnen meldt til akutt keisersnitt med hastegrad 1, hvor man umiddelbart overflyttes til operasjonssal for keisersnitt i narkose.

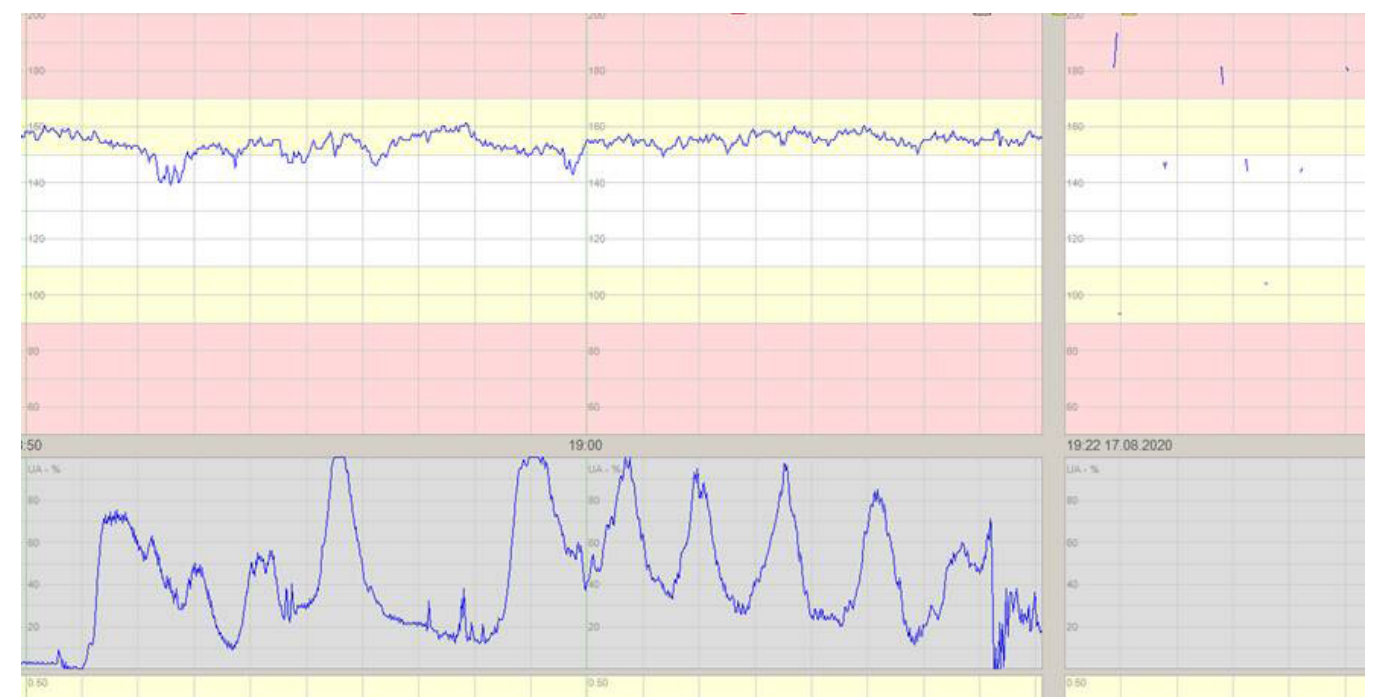

Figur 1 Kardiotokografi (CTG) viser fosterets hjertefrekvens (øverste kurve), som ligger over normalområdet (det hvite feltet). Rieregistreringen (nederste kurve) viser hyppige rier før CTG-apparatet ble koblet av. Etter påkobling 13 minutter senere hørte jordmor en hjertefrekvens mellom 70 og 90 slag per minutt hos fosteret, og man ser ingen rier på rieregistreringen.

Ved laparotomi tømte det seg koagler og blodtilblandet væske fra bukhulen. Det ble utført uterotomi på vanlig måte. Fostervannet var blakket. Det ble forløst et blekt, slapt barn fra hodeleie. Ved forløsning av placenta ble denne funnet i fri bukhule, og det ble palpert tarm i uterinhulen samt en $12 \mathrm{~cm}$ lang uterusruptur som strakk seg fra høyre til venstre tubehjørne langs hele fundus uteri (figur 2). 


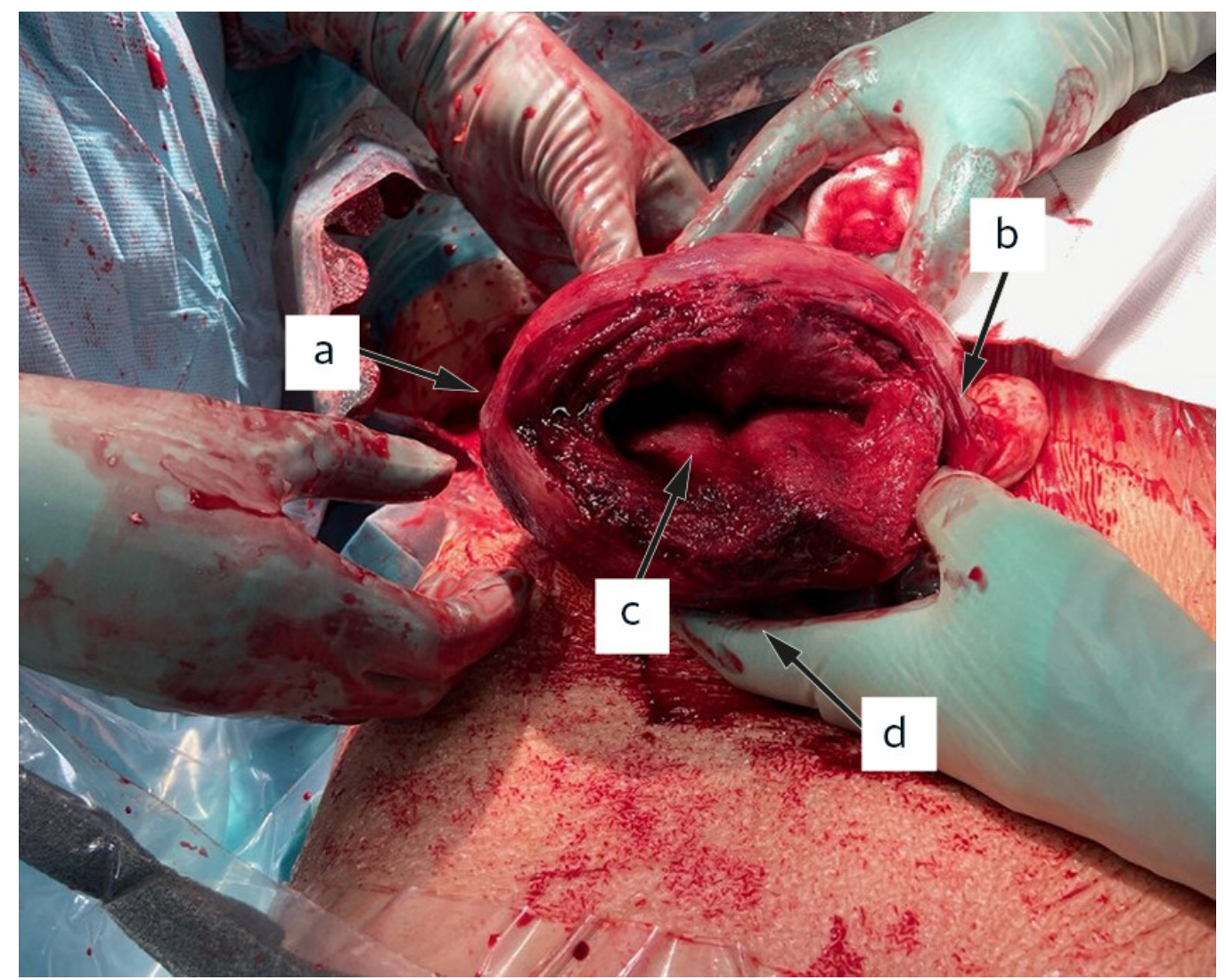

Figur 2 Stor uterusruptur som strekker seg fra høyre (a) til venstre (b) tubehjørne inn til uterinkaviteten (c). Uterotomi synes ikke på bildet, men ligger på fremre vegg (d). Uterotomi og uterusruptur ble suturert i to lag. Blødningsmengde totalt var $600 \mathrm{~mL}$, og kvinnen var stabil under hele inngrepet. Barnet veide $3990 \mathrm{~g}$, apgarscore var 1-1-4 etter henholdsvis ett, fem og ti minutter. Blodgassanalyse fra navlevenen viste $\mathrm{pH}$ 6,74 (referanseområde 7,17-7,48) og baseoverskudd -13,4 (-9 til -1), som tilsa alvorlig fosterasfyksi. Barnet ble intubert og hypotermibehandlet i 72 timer i henhold til retningslinjer (1).

Det postoperative forløpet var ukomplisert for kvinnen. Barnet ble utskrevet i velbefinnende ti dager etter forløsning og utviklet seg normalt.

\section{Diskusjon}

Uterusruptur er en alvorlig obstetrisk hendelse som er assosiert med høy perinatal og maternell morbiditet og mortalitet (므). I en norsk studie fant man etter komplett ruptur $15 \%$ perinatal død, $23 \%$ overflytting til nyfødtintensivavdeling og 6,1\% hypoksisk iskemisk encefalopati (3). Forekomsten av komplett ruptur er i Norden 5,6 per 10 ooo fødsler. Ved tidligere gjennomgått keisersnitt øker forekomsten til 5 per 1 ooo fødsler (4). De viktigste risikofaktorene for uterusruptur er tidligere operative inngrep på uterus og induksjon av fødsel. Spesielt kombinasjonen av prostaglandiner og oksytocin under induksjon har vist å øke risikoen $(5, \underline{6})$.

Vår pasient var tidligere operert med salpingektomi, og fødselen ble indusert med misoprostol - et prostaglandin - på overtid. Hun hadde de hyppigst forekommende symptomene ved uterusruptur, som er smerter som ikke opphører mellom riene, og patologisk kardiotokografi. Fordi det er svært sjelden at uterusruptur forekommer hos førstegangsfødende, var ikke dette noe man mistenkte til å begynne med. Andre symptomer kan være plutselig opphør av rier, vaginalblødning, at forliggende fosterdel forsvinner ved vaginal eksplorasjon, peritoneal irritasjon, blodtrykksfall, sjokk eller død (7.). Ved mistenkt uterusruptur er tiltaket umiddelbar forløsning av barnet og placenta, oftest med laparotomi. 
Operasjonsbeskrivelse fra salpingektomien ble innhentet post partum. Der ble det beskrevet en svært proksimal, blålig dilatasjon av egglederen forenelig med interstitiell ekstrauterin graviditet. En interstitiell ekstrauterin graviditet er lokalisert i den proksimale delen av egglederen, beliggende i den muskulære delen av uterinveggen. Forekomst av interstitiell ekstrauterin graviditet utgjør 2-4\% av alle tubarsvangerskap (ㅁ), og tilstanden behandles oftest kirurgisk med kilereseksjon (9.). Hos vår pasient ble det for å oppnå blødningskontroll satt vasopressin i myometriet nær tubehjørnet, og sårflatene ved tubehjørnet ble suturert. Høyre eggleder ble deretter fjernet. Det ble ikke gjort kilereseksjon av tubehjørnet.

Laparoskopi er foretrukket ved operative inngrep på uterus eller adneks, og selv om det forekommer svært sjelden, er uterusruptur kjent som mulig komplikasjon, spesielt etter laparoskopisk myomektomi (므). Få studier beskriver risiko for uterusruptur etter laparoskopisk salpingektomi. Likevel beskriver flere kasuistikker og retrospektive studier at det ved interstitiell graviditet med primær kirurgisk behandling er risiko for ruptur ved senere graviditeter, spesielt ved kilereseksjon av tubehjørnet $(5, \underline{11})$. En norsk studie fra 2019 inkluderte 33 pasienter som ble operert med kilereseksjon grunnet interstitiell graviditet (12). Kontrollgruppen besto av pasienter som hadde gjennomgått laparoskopisk salpingektomi på grunn av ikke-interstitiell ekstrauterin graviditet. Studien undersøkte forløsningsmetode og risiko for uterusruptur, og fant to tilfeller av uterusruptur blant de 33 kvinnene. Ved senere fødsler ble 60 \% av kvinnene i kasusgruppen forløst med keisersnitt,

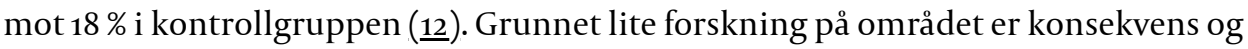
dermed anbefaling for senere graviditet uklar.

Trolig har en kombinasjon av tidligere operativt inngrep og induksjon vært medvirkende til uterusruptur hos vår pasient. Med dagens kunnskap er det ikke nødvendigvis slik at en ekstrauterin graviditet i uterinhjørnet bør føre til anbefaling om planlagt keisersnitt, men man bør være bevisst på at uterusruptur er en komplikasjon som kan oppstå, spesielt dersom fødselen induseres. Denne kasuistikken illustrerer viktigheten av å innhente journaldokumenter fra andre sykehusinnleggelser for å få en fullstendig anamnese. I dette tilfellet kunne det ha bidratt til en annen vurdering av fødselsinduksjon og til raskere diagnostisering og forløsning av barnet.

Kvinnen er informert om mulige årsaker til hennes uterusruptur og at hun ved neste svangerskap anbefales forløsning med planlagt keisersnitt.

Pasienten og barnefar har gitt samtykke til at artikkelen blir publisert. Artikkelen er fagfellevurdert.

LITTERATUR

1. Klingenberg C, Støen R, Moster D et al. Terapeutisk hypotermi ved perinatal asfyksi. Pediatriveiledere fra Norsk barnelegeforening. https://www.legeforeningen.no/contentassets/o6a7a1f5110c418db68b71d32753c81e/terapeutiskhypotermi-ved-perinatal-asfyksi-nasjonalprosedyre-finalo81117.docx Lest 10.1.2021.

2. Colmorn LB, Petersen KB, Jakobsson M et al. The Nordic Obstetric Surveillance Study: a study of complete uterine rupture, abnormally invasive placenta, peripartum hysterectomy, and severe blood loss at delivery. Acta Obstet Gynecol Scand 2015; 94: 734-44. [PubMed][CrossRef]

3. Al-Zirqi I, Daltveit AK, Vangen S. Infant outcome after complete uterine rupture. Am J Obstet Gynecol 2018; 219:109.e1-8. [PubMed][CrossRef]

4. Al-Zirqi I, Stray-Pedersen B, Forsén L et al. Uterine rupture after previous caesarean section. BJOG 2010; 117: 809-20. [PubMed][CrossRef]

5. Chao AS, Chang YL, Yang LY et al. Laparoscopic uterine surgery as a risk factor for uterine rupture during pregnancy. PLoS One 2018; 13: e0197307. [PubMed][CrossRef]

6. Al-Zirqi I, Daltveit AK, Forsén L et al. Risk factors for complete uterine rupture. Am J Obstet Gynecol 2017; 216:165.e1-8. [PubMed][CrossRef]

7. Al-Zirqi I, Tappert C. Uterusruptur. Veileder i fødselshjelp.

https://www.legeforeningen.no/foreningsledd/fagmed/norsk-gynekologisk- 
forening/veiledere/veileder-i-fodselshjelp/uterusruptur Lest 10.1.2021.

8. Lau S, Tulandi T. Conservative medical and surgical management of interstitial ectopic pregnancy. Fertil Steril 1999; 72: 207-15. [PubMed][CrossRef]

9. Svenningsen R, Langebrekke A, Qvigstad E. Interstitielle graviditeter-diagnostikk og behandling. Tidsskr Nor Laegeforen 2007; 127: 2242-4. [PubMed]

10. Gambacorti-Passerini Z, Gimovsky AC, Locatelli A et al. Trial of labor after myomectomy and uterine rupture: a systematic review. Acta Obstet Gynecol Scand 2016; 95: 724-34, 4. [PubMed] [CrossRef]

11. Hoyos LR, Vilchez G, Allsworth JE et al. Outcomes in subsequent pregnancies after wedge resection for interstitial ectopic pregnancy: a retrospective cohort study. J Matern Fetal Neonatal Med 2019;32: 2354-6o. [PubMed][CrossRef]

12. Svenningsen R, Staff AC, Langebrekke A et al. Fertility outcome after cornual resection og interstitial pregnancies. J Minim Invasive Gynecol 2019; 26: 865-70. [PubMed][CrossRef]

Publisert: 20. september 2021. Tidsskr Nor Legeforen. DOI:10.4045/tidsskr.21.0085

Mottatt 29.1.2021, første revisjon innsendt 11.4.2021, godkjent 10.5.2021.

Publisert under åpen tilgang CC BY-ND. Lastet ned fra tidsskriftet.no 26. april 2023. 